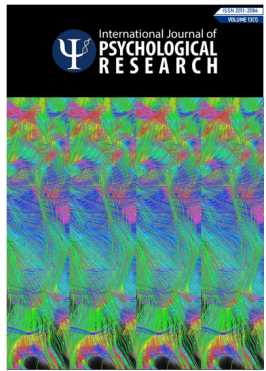

Vol $13, \mathrm{~N}^{\circ} 1$

https://revistas.usb.edu.co/index.php/IJPR ISSN 2011-2084

E-ISSN 2011-7922

\section{Preliminary Study on Psychome- tric Properties of an Anxiety Scale in Down Syndrome with Anxiety Symptoms}

Propiedades psicométricas preliminares de una escala de ansiedad en síndrome de Down con síntomas de ansiedad

\author{
David Sánchez-Teruel ${ }^{1}$, María Auxiliadora Robles-Bello ${ }^{2 \star}$ \\ ${ }^{1}$ Department of Psychology, Universidad de Córdoba, Córdoba, España. \\ ${ }^{2}$ Department of Psychology, Universidad de Jaén, Jaén, España.
}

\begin{abstract}
.
Background: anxiety remains one of the most common disorders in typically developing children and young adults. Adolescents with Down syndrome (DS) lack diagnostic tests for evaluation. Methods: this study evaluated the psychometric properties of the Screen for Child Anxiety Related Emotional Disorders inventory in its self-report version in 63 adolescents with anxiety symptoms with DS. The inclusion criteria for the studies were trisomy 21 and a chronological age between 8 and 17 years. Psychometric properties arestrictly evaluated with the sample exceeding a cutoff point in anxiety symptomatology. A confirmatory factorial analysis tested two models for the new evaluation test. Results: both models confirmed a four-factor structure (somatic/panic, social phobia, generalized anxiety, and separation anxiety). Model 2, nevertheless, had fewer items and a better fit, and it also showed a high correlation with other anxiety detection measures and adequate internal consistency. Conclusions: the importance of validating psychopathological anxiety tests for children and young people with DS in order to build good mental health is discussed, emphasizing the need to provide easy and short-term tests on cognitive and emotional aspects in people with intellectual disabilities.
\end{abstract}

Resumen.

Antecedentes: la ansiedad sigue siendo uno de los trastornos más frecuentes en niños y jóvenes con un desarrollo típico. Sin embargo, los adolescentes con síndrome de Down (SD) carecen de pruebas diagnósticas para su evaluación. Métodos: este estudio evaluó las propiedades psicométricas del inventario de Screen for Child Anxiety Related Emotional Disorders en su versión de autoinforme en 63 adolescentes con síntomas de ansiedad con SD. Los criterios de inclusión de los estudios fueron trisomía 21 y una edad cronológica de entre 8 y 17 años. Las propiedades psicométricas se evalúan estrictamente con la muestra que excede un punto de corte en sintomatología de ansiedad. Un análisis factorial de confirmación probó dos modelos para la nueva prueba de evaluación. Resultados: ambos modelos confirmaron una estructura de cuatro factores (somático/pánico, fobia social, ansiedad generalizada, y ansiedad por separación). El modelo 2, no obstante, tenía menos items y un mejor ajuste, y también mostró una alta correlación con otras medidas de detección de ansiedad y una consistencia interna adecuada. Conclusiones: se discute la importancia de validar las pruebas psicopatológicas de ansiedad para niños y jóvenes con SD con el fin de construir una buena salud mental, enfatizando la necesidad de proporcionar pruebas fáciles y de corta duración sobre aspectos cognitivos y emocionales en personas con discapacidad intelectual.

Keywords.

Down syndrome; Anxiety; Assessment; Validity; Factor analysis.

Palabras Clave.

Síndrome de Down; Ansiedad; evaluación; validación; análisis factorial. 


\section{Introduction}

The assessment of anxiety symptoms in children and youth with Down syndrome (hereinafter DS) is steadily gaining wider clinical interest (Borrel, 2012; Garvía, Benejam, \& Borrel, 2010). However, few research studies focus on exploring this construct in people with intellectual disability, despite prevalence rates tripling that of typically developing populations (Esbensen, Rojahn, Aman, \& Ruedrich, 2003; Klein et al., 2018; Robles-Bello, Valencia, \& Sánchez-Teruel, 2018; Whitney, Shapiro, Warschausky, Hurvitz, \& D., 2018).

Likewise, availing of anxiety screening tools adapted to children and youth with DS is seen as a priority (Fink, Deighton, Humphrey, \& Wolpert, 2015; Klein et al., 2018; Sentenac et al., 2011), given that there are several tools available to assess anxiety in children and youth with typical development (American Psychiatric Association, 2014).

There are, however, some limitations to screening anxiety in people with intellectual disability (White, Oswald, Ollendick, \& Scahill, 2009). First, questions have been raised about the validity of self-report measures administered to people with developmental disorders, and the information provided by their parents and guardians regarding anxiety symptomology is not guaranteed to be accurate (Mazzone, Ruta, \& Reale, 2012). Second, carrying out a differential diagnosis of comorbidity with other disorders is no easy task (Flórez, Garvía, \& Fernández-Olari, 2015). Fortunately, studies involving children born between the 1960s and the late 1980s reported lower performance levels than subsequent studies including children born in the 1990s, owing to the generalized nature of the early interventions received from birth (Couzens, Cuskelly, \& Haynes, 2011; Couzens, Haynes, \& Cuskelly, 2012). Thus, there are numerous studies in which these populations are recruited from a more current cohort, which has seen their cognitive level, reading skills, and academic skills in general improve, and which suggests that they may be eligible for anxiety symptom screening using self-report measures (Cleland, Wood, Hardcastle, Wishart, \& Timmins, 2010; Lanfranchi, A., S., \& R., 2012; Naess, Melby-Lervåg, Hulme, \& Lyster, 2012; Stern, Gadgil, Blakeley-Smith, Reaven, \& Hepburn, 2014).

Scientific literature has given rise to several instruments that can be used to assess anxiety in children and youth from the general population. For example, the Spence Children's Anxiety Scale (SCAS) developed by Spence (1997), the Revised Child Anxiety and Depression Scale (RCADS) of Chorpita, Yim, Moffitt, Unemoto, and Francis (2000) and the Youth Anxiety Measure for DSM-5 (YAM-5) by Muris et al. (2017). However, they seem to present a number of psychometric difficulties when it comes to adapting them to the general population in Spain. Specifically, the Spanish version of the
SCAS for children and youth contains a low to moderate effect size (.20 and .50), and several elements (subdimensions of separation anxiety, social phobia, and fears) have a relatively weak relationship (factorial weights under .50) with their assigned scale (Godoy, Gavino, Carrillo, Cobos, \& Quintero, 2011). In addition, it has only been adapted for children between 8 and 12 years old of general population, which could make it difficult to generalize to adolescents (Orgilés, Méndez, Spence, Huedo-Medina, \& Espada, 2011), and the test-retest reliability of the SCAS has not been assessed (Orgilés, Fernández-Martínez, Guillén-Riquelme, Espada, \& Essau, 2016). On the other hand, the RCADS assesses depressive symptoms together with anxious symptoms, and it has been adapted only in Spanish adolescents (11 to 17 years) of general population, detecting low correlations between subdimensions (generalized anxiety and major depressive), and the test-retest reliability of this scale has not been evaluated (Sandín, Valiente, \& Chorot, 2009; Piqueras, Martín-Vivar, Sandin, San Luis, \& Pineda, 2017). Furthermore, in the YAM-5 there are some items which are not easily adaptable to Spanish youth from a cross-cultural and language-specific perspective (Garcia-Lopez, Saez-Castillo, \& Fuentes-Rodriguez, 2016).

There are other instruments such as the Screen for Child Anxiety Related Disorders (SCARED) inventory, which boast good psychometric properties (Birmaher et al., 1997, 1999). This measure has also demonstrated methodological robustness in typically developing Chinese children and youth (Su, Wang, Fan, Su, \& Gao, 2008). Another version of the SCARED reported suitable psychometric properties in Brazilian adolescents with typical development (Isolan, Salum, Osowski, Amaro, \& Manfro, 2011). Nevertheless, there are structural difficulties (between three and five factors) with this scale in its cross-cultural adaptation for use among typically developing children and youth (Hale, Crocetti, Raaijmakers, \& Meeus, 2011). Other studies have assessed the psychometric properties of the SCARED in children and adolescents with typical development and with autism, showing high internal consistency in both populations (alpha $=0.90)$ (Stern et al., 2014; Van-Steensel, Deutschman, \& Bögels, 2013). In addition, SCARED would be the best tool to be validated by people with intellectual disability or Down Syndrome, because it uses simpler language and because there are previous studies with disabled population, specifically with autism spectrum disorder (Stern et al., 2014).

However, we are unaware of any SCARED adaptations for children and youth with chromosomal disorders and intellectual disability, as is the case of DS.

Our aim in this research study was to examine the psychometric characteristics of the Spanish SCARED inventory in children and youth with Down syndrome, conducting an analysis of the SCARED's factorial struc- 
ture by using confirmatory factor analysis. We hypothesized that SCARED will demonstrate strong internal consistency and will conform to a four-factor structure, similar to the Spanish version of Vigil-Colet et al. (2009).

\section{Method}

\subsection{Participants}

This methodological cross-sectional study included 172 children and youth with Down syndrome (DS) participating in the study. Everyone from the sample attended a public mainstream school (inclusive classroom setting) on a part-time basis. Study inclusion criteria were having trisomy 21, a chronological age of between 8 and 17 years, a minimum IQ of above/below two standard deviations (59) on the Spanish adaptation of kaufman's Brief Intelligence Test - K-BIT (Test Breve de Inteligencia; Cordero \& Calonge, 1997), not diagnosed with autism or suspected of having autism symptoms, and having a good level of reading comprehension, sufficient ability to grade the anxiety levels of each reagent.

Permission was first sought from the centres and then from the families whose children participated in the study. Participants were then divided into two groups using the Escala de Ansiedad para Niños de Spence (Spence Children's Anxiety Scale, SCAS; Spence, 1997), translated into Spanish by Godoy et al. (2011). There were 63 participants (36.6\% of the total sample) with anxiety symptoms (SCAS $>36$ points) (Olofsdotter, Sonnby, Vadlin, Furmark, \& Nilsson, 2016; Whiteside \& Brown, 2008), to whom we assigned the acronym DSAS, and 109 participants showed no signs of this disorder (DSWAS) (see Table 1).

\subsection{Instruments}

Spence Children's Anxiety Scale (SCAS) developed by Spence (1997). We used the Spanish version of this scale adapted by Godoy et al. (2011), which screens anxiety in children and youth from the general population. It comprises 38 items with 4 response options, ranging from 0 (never) to 3 (always). The questionnaire covers six subscales: panic disorder and agoraphobia, separation anxiety, social phobia, physical injuries fear as representing specific phobias, obsessive-compulsive disorder, and generalized anxiety. Internal consistency (Cronbach's alpha) of the total score in Spanish samples was .92, and the subscales' alphas ranged from .81 (panic-agoraphobia) to .61 (separation anxiety and physical injuries fear). Test-retest reliability (intraclass correlation) of the total score was reported to be .61, and for the subscales it ranged from .62 (physical injuries fear) to .51 (panic-agoraphobia). In this sample of children and youth with DS, the Cronbach's alpha was .83 for the scale total and between .78 and .89 for each SCAS subscale.
Screen for Child Anxiety Related Disorders (SCARED; Birmaher et al., 1999) (translated into Spanish by VigilColet et al., 2009). This instrument screens for anxiety in children and youth (8 to 18 years) and comes in two versions: a self-report questionnaire for the child and another for their parents. Only the self-report measure was used for this research. The Spanish SCARED contains 41 statements for children and youth, formulated in the following way: "People tell me that I look nervous", and which elicit responses on a 3-point Likert-type scale: $(0$ $=$ Almost never $1=$ Sometimes; $2=$ Often $)$. The original version of the SCARED had 38 items (Birmaher et al., 1997); however, given the difficulty in discriminating between the social phobia factor and other anxiety disorders, three more items were added, bringing the total item in the definitive English version to 41 (Birmaher et al., 1999). It is divided into five subscales (Generalized Anxiety Disorder-GAD, Panic Disorder-PA, Separation Anxiety Disorder-SAD, Social Phobia-SP, and School Avoidance), allowing us to obtain the scale's total score and the scores for each subscale. The original English study set a clinically significant cut-off score of 25 points for typically developing children and youth (Birmaher et al., 1999). Earlier studies carried out on the psychiatric population have demonstrated adequate convergent and discriminant validity for disruptive behavior disorders and depressive disorders based on the Child Behavior Checklist (CBCL Achenbach \& Edelbrock, 1980), high internal consistency (alpha $=.93$ total; .74 to .89 for the subscales), and high sensitivity (.71) and specificity (.67) (Birmaher et al., 1997). Cross-cultural adaptations in Spanish children (8 to 12 years) from the general population have observed a four-factor structure in the SCARED, made up of the following subscales: somatic/panic (SO/PA), social phobia (SP), generalized anxiety (GA), and separation anxiety (SA) (Vigil-Colet et al., 2009). More recent studies on Spanish youth (12 to 19 years) have yielded adequate psychometric properties across all subscales (alpha $=.41-.71)$ and significant measurement invariance when differentiating between adolescents with and without social anxiety (Hale et al., 2013). In the total sample of children and youth with DS from this manuscript, Cronbach's alpha was .73 for the total scale and .51 to .69 for each SCARED subscale.

\subsection{Procedure}

First, we requested the Spanish-language version of the SCARED from its authors (Vigil-Colet et al., 2009). We then contacted 18 Down syndrome associations from across several provinces in southern and central Spain to find out if they wished to participate in the study. Parents initiated contact with the research clinic and completed a brief telephone screen for eligibility. If the child was potentially eligible for the study, the family was invited to attend a clinic session, where informed consent was obtained prior to initiating any data gath- 
Table 1

Scores obtained on the K-BIT and SCAS by children and youth from both groups alongside the effect size of the between-group differences

\begin{tabular}{|c|c|c|c|c|c|}
\hline & $\mathrm{DS}_{\mathrm{AS}} \mathrm{M}(\mathrm{SD})$ & $\mathrm{DS}_{\mathrm{WAS}} \mathrm{M}(\mathrm{SD})$ & $t$ & $p$ & $\begin{array}{c}\text { Eta } \\
\text { squared }\end{array}$ \\
\hline \multicolumn{6}{|l|}{ Sex } \\
\hline Male & 26 & 55 & \multirow[b]{2}{*}{19.27} & \multirow[b]{2}{*}{0.95} & \multirow[b]{2}{*}{0.09} \\
\hline Female & 37 & 54 & & & \\
\hline Age & $9.1(1.76)$ & $11.01(1.86)$ & 11.43 & .84 & .06 \\
\hline K-BIT TOTAL & $61.31(14.97)$ & $61.90(10.28)$ & 14.12 & .47 & .04 \\
\hline Vocabulary & $57.31(14.82)$ & $59.30(10.20)$ & 11.22 & .71 & .08 \\
\hline Matrices & $63.03(15.67)$ & $63.80(8.10)$ & 13.78 & .42 & .06 \\
\hline SCAS TOTAL & $35.82(17.5)$ & $7.68(11.9)$ & 17.20 & .00 & .17 \\
\hline Panic disorder/agoraphobia & $5.48(4.9)$ & $1.55(2.4)$ & 16.70 & .00 & .13 \\
\hline Separation anxiety & $4.39(3.6)$ & $1.30(2.4)$ & 18.20 & .02 & .14 \\
\hline Fears & $3.12(2.4)$ & $1.35(2.1)$ & 19.11 & .02 & .09 \\
\hline Social phobia & $6.28(4.2)$ & $3.10(3.1)$ & 11.45 & .04 & .11 \\
\hline Obsessions/Compulsions & $7.11(4.1)$ & $2.18(3.1)$ & 19.30 & .00 & .16 \\
\hline Generalized anxiety & $8.92(3.6)$ & $3.21(2.3)$ & 15.26 & .00 & .08 \\
\hline
\end{tabular}

Note. $\mathrm{DS}_{\mathrm{AS}}=$ Down syndrome with anxiety symptoms; $\mathrm{DS}_{\mathrm{WAS}}=$ Down syndrome without with anxiety symptoms

ering activities. If the participant met the eligibility criteria, parents were invited to continue in the process of evaluating their children. In the next session, the evaluation with the anxiety test was carried out. Families were not financially compensated for their participation.

Both questionnaires (SCARED and SCAS) were completed by the participants themselves in the presence of psychologists working with the association to which they belong. This research study was approved by the bioethics committee attached to the first author's university: University of Jaén (Spain) (code: DIC.18/9.PRY).

\subsection{Data Analysis}

IBM SPSS statistics 23 was used to run an analysis on the descriptive aspects of the samples, and a confirmatory factor analysis (CFA) using AMOS version 7 (American Psychiatric Association, 2006) was performed in order to validate the SCARED's four-factor structure in its Spanish version. Maximum likelihood (ML) with bootstrap procedures (owing to multivariate non-normality) was the method used to conduct the confirmatory analysis. When sample size is less than 300 participants, maximum likelihood (ML) estimation with bootstrap procedures yields the best results, even under conditions that do not meet multivariate normality assumption (RodríguezAyán \& Ruiz-Díaz, 2008). The fit indices used were the $\chi^{2} / \mathrm{df}$ ratio, Root Mean Square Error of Approximation (RMSEA), Standardized Root Mean Square Residual (SRMR), Comparative Fit Index (CFI), Tucker-Lewis Index (TLI) and AGFI (Adjusted goodness-of-fit index), GFI (Gamma index), and Akaike Information Criteria (AIC). The goodness-of-fit model is deemed satisfactory if TLI and CFI $\geq .95$, AGFI and GFI $\geq .90$, the RMSEA is close to .06 and the SRMR indicates a good fit if it is below the .05 value (Hu \& Bentler, 1999; Kline, 2016). Descriptive and reliability analyses of the resulting scale were also carried out.

\section{Results}

3.1 SCARED results in a pilot sample $\left(D^{2} S_{A S}=10\right)$

The results corresponding to questionnaire comprehension in the pilot subsample of children and youth with DS $(n=10)$ revealed comprehension difficulties for SCARED items 3, 13, 17, 39, and 40. Most participants (93\%) scored lower than expected in item understanding (less than 5 on a scale of $0=$ incomprehensible to $10=$ completely comprehensible). Assessment of the scale in terms of the time elapsed between starting and completing the questionnaire, without taking into account the time spent going over the items to check for understanding, averaged 51 minutes for the total scale. Following an analysis of the aforementioned results, the decision was taken to rephrase all items that participants in this sample found difficult to understand, as shown in Table 2.

\subsection{Confirmatory factor analysis $\left(D S_{\mathrm{AS}}=63\right)$}

The results from the multivariate normality analysis for the sample of children and youth with DS indicated no multivariate normality in item distribution (Mardia $=$ 437.51).

The results shown in Figure 1, displayed as a path diagram of the complete SCARED (Model 1), confirm the questionnaire's four subscales. Specifically, the factor loadings were found in somatic/panic (.12), social phobia (.33), generalized anxiety (.29), and separation anxiety (.71). However, low beta $\beta$ coefficients were observed in some subscales. Specifically, item 6 (.17), item 12 
Table 2

Changes to some SCARED items

\begin{tabular}{|c|c|c|}
\hline 3 & $\begin{array}{l}\text { I don't like to be with } \\
\text { people I don't know } \\
\text { well }\end{array}$ & $\begin{array}{l}\text { I don't like to be } \\
\text { around strangers }\end{array}$ \\
\hline 13 & $\begin{array}{c}\text { I worry about sleeping } \\
\text { alone }\end{array}$ & $\begin{array}{c}\text { I don't like sleeping } \\
\text { alone }\end{array}$ \\
\hline 17 & $\begin{array}{c}\text { I worry about going to } \\
\text { school }\end{array}$ & $\begin{array}{l}\text { I don't like going to } \\
\text { school }\end{array}$ \\
\hline 39 & $\begin{array}{l}\text { I feel nervous when I } \\
\text { am with other children } \\
\text { or adults and I have to } \\
\text { do something while } \\
\text { they watch me (for } \\
\text { example, reading out } \\
\text { loud, talking, playing, } \\
\text { practising sport, etc.) }\end{array}$ & $\begin{array}{l}\text { I feel nervous when I } \\
\text { have to do something } \\
\text { (for example, reading } \\
\text { out loud, talking, } \\
\text { playing, practising } \\
\text { sport, etc.) and other } \\
\text { people are watching me }\end{array}$ \\
\hline 40 & $\begin{array}{l}\text { I feel nervous when I } \\
\text { am going to parties, } \\
\text { dances or any place } \\
\text { where there will be } \\
\text { people that I don't } \\
\text { know well }\end{array}$ & $\begin{array}{l}\text { I feel nervous when I } \\
\text { have to go somewhere I } \\
\text { don't know anyone }\end{array}$ \\
\hline
\end{tabular}

(.03), and item 15 (.13) in somatic/panic (SO/PA); item 5 (.19) and item 31 (.10) in generalized anxiety (GA); and item 16 (.19), item 20 (.19), and item 30 (.09) in separation anxiety (SA). Furthermore, the covariance between subscales was adequate (.11 to .43 ).

The results displayed in Figure 2, a path diagram in which the low factor loading items have been removed (Model 2), continues to show the four-dimensional structure of the SCARED, but with better loadings in each subscale (between .49 and .89). Furthermore, no low standardized loading values (beta $\beta$ coefficients) were found for any of the subscales. The covariance between subscales was adequate (.21 to .51).

If we look at the results in Table 3 , we can see that the SCARED yields better adjustment indices in Model 2 for the sample of children and youth with DS (DS $\mathrm{AS}_{\mathrm{S}}$ $=63$ ). Specifically, $\chi^{2} / \mathrm{df}$ was found to be adequate and significant in Model 2 but not in Model 1. The remaining indices were excellent in Model 2, obtaining an RMSEA value (95\% CI) below 0.08, and with GFI and AGFI values above the 0.85 limit, achieving consensus among the goodness-of-fit indices under evaluation. Thus, model acceptability and goodness-of-fit was strong.

\subsection{Criterion validity of the SCARED-DS $\left(D_{A S}=63\right)$}

Regarding criterion validity through convergent validity, Table 4 shows the correlations between the SCARED-DS subscales/total and the SCAS (Spence, 1997). The total score of the SCARED-DS and each one of its subscales highly correlate with the total score of the SCAS.

\subsection{Internal consistency and reliability using the split- half method of the SCARED-DS $\left(D_{A S}=63\right)$}

The normality analysis revealed no univariate normality, as it can be seen from the Kolmogorov-Smirnov test. Furthermore, skewness and kurtosis showed no excessive variability $(-2 ; 2)$. The results corresponding to the internal consistency of all four subscales and the total SCARED-DS score were calculated using cronbach's alpha, recording very high alphas across all dimensions and in the total score. Split-half reliability was tested for each dimension andfor the complete SCARED-DS scale (30 items), also reporting high coefficients (Table 5).

\section{Discussion}

This research aims to be the first to provide a useful tool for screening anxiety in children and youth with Down syndrome (Stern et al., 2014). The assessment and solution-seeking approach to anxiety symptoms, especially in children and young people with some type of developmental disorder or disability, represents not only a major challenge for researchers and professionals working with these populations, but also addresses the continuing demand from their families, as outlined in previous studies (Foley et al., 2016).

Building on anxiety research into people with disabilities, and being able to offer valid assessment tools and interventions adapted to the type of disability and population, is a challenge that can be met through new confirmatory analysis procedures (Flórez et al., 2015; Simonoff et al., 2008). The results of this study suggest that the SCARED is a valid and clinically useful tool for assessing anxiety in children and youth with DS and who have similar characteristics to the sample used, and who may also be eligible for specialized clinical treatment.

The SCARED-DS, as it has been named, has demonstrated strong psychometric properties in the sample of children and youth with DS, although it contains a fewer number of items than the test used on samples with typical development (Hale et al., 2013) and autism (Stern et al., 2014). This was after rewording five items which participants found confusing during the pilot study, and then eliminating those items which had very low loadings across the different subscales, especially in somatic/panic, leaving us with a series of items with adequate loadings on all four anxiety-measuring subscales.

With regard to confirmatory factor analysis, very low standardized loading values were observed in some subscales (Figure 1). Furthermore, the covariance between subscales was adequate, indicating no dependence between these SCARED factors among these children and youth with DS and anxiety. However, in Figure 2 continues to show the four-dimensional structure of the SCARED, but with better loadings in each subscale. Furthermore, no low standardized loading values (beta $\beta$ coefficients) were found for any of the subscales. The 


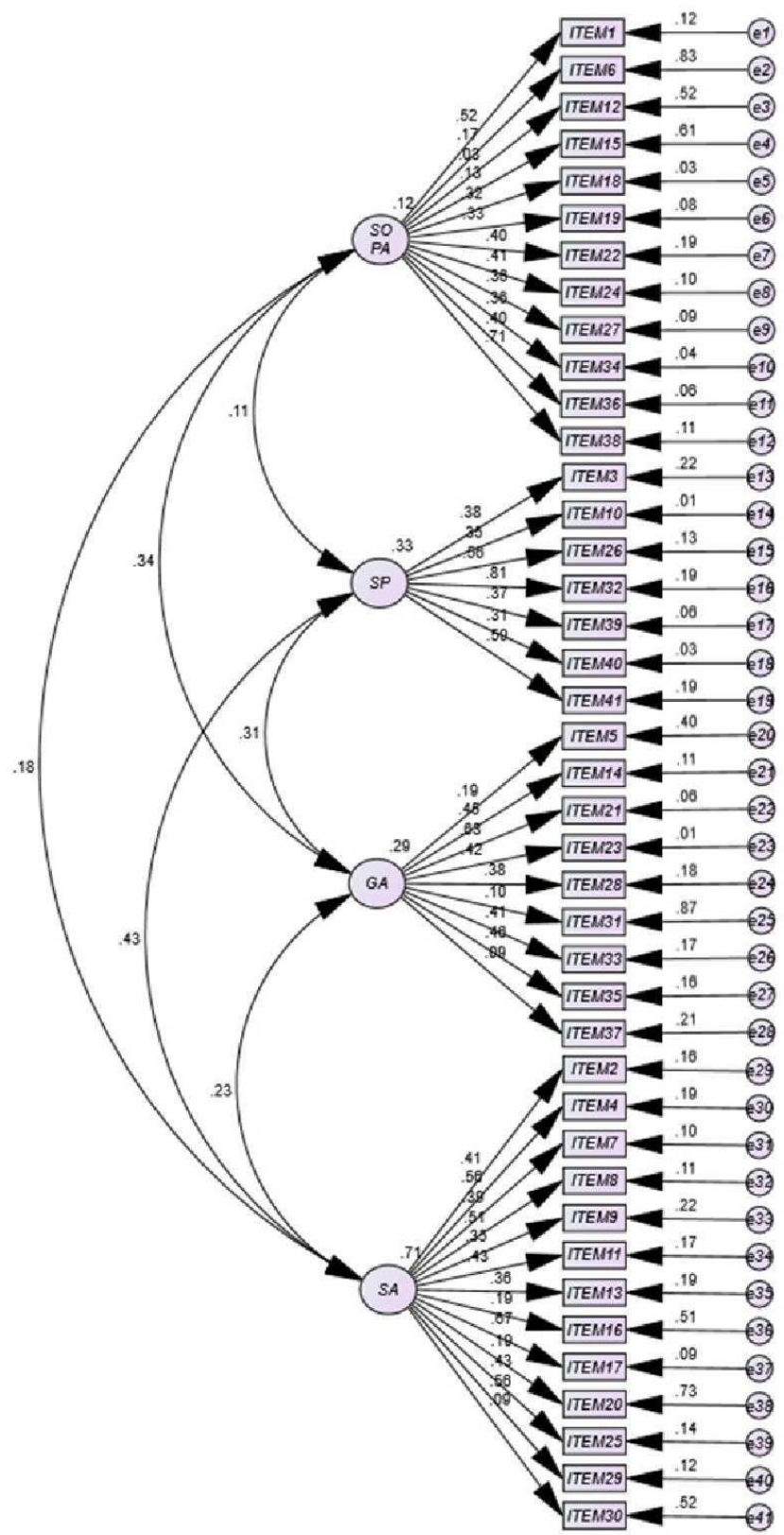

Figure 1. Path diagram of the four-dimensional model corresponding to the SCARED in children and youth with DS $\left(\mathrm{DS}_{\mathrm{AS}}=63\right)($ Model 1$)$. SO/PA = somatic/panic; $\mathrm{SP}=$ social phobia; $\mathrm{GA}=$ generalized anxiety; SA = separation anxiety.

Note. The between-dimension correlations are shown using two-way arrows. The standardized B coefficients are placed above each one-way arrow. The between-dimension covariance loadings are shown in the two-way arrows.

covariance between subscales was adequate (.21 to .51), indicating no dependence between these factors. In addition, the following are provided results of comparative or parsimonious adjustment (Table 3) The indices (CFI and TLI were excellent in Model 2), and the AIC index proves that model 2 is the most suitable because it is the model with the least AIC, so it is the most parsimonious. Thus, model acceptability and goodness-of-fit was strong.
The factor loadings on the somatic/panic and generalized anxiety subscales for people with autism spectrum disorders (ASDs) and Down syndrome (DS) differ from typical populations, according to earlier studies (Birmaher et al., 1997; Stern et al., 2014). These results may be explained by the fact that typically developing young people might interpret generalized anxiety items as a fear of receiving negative peer evaluations, an as- 


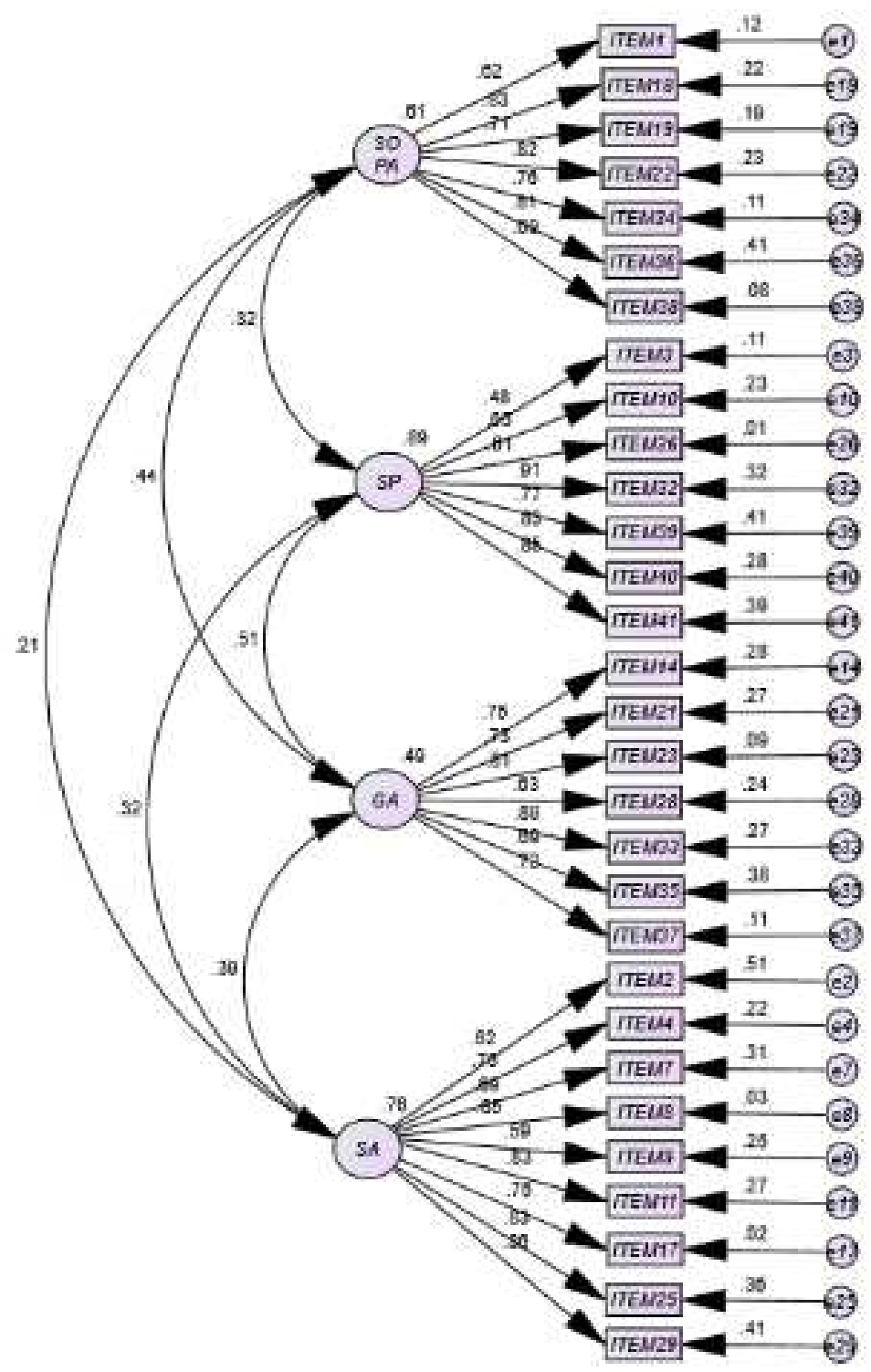

Figure 2. Path diagram of the four-dimensional model corresponding to the SCARED in children and youth with DS $\left(\mathrm{DS}_{\mathrm{AS}}=63\right)($ Model 2$) . \mathrm{SO} / \mathrm{PA}=$ somatic/panic; $\mathrm{SP}=$ social phobia; $\mathrm{GA}=$ generalized anxiety; $\mathrm{SA}$ = separation anxiety.

Note. The between-dimension correlations are shown using two-way arrows. The standardized B coefficients are placed above each one-way arrow. The between-dimension covariance loadings are shown in the two-way arrows.

pect which does not arise in the ASD population mainly (Ben-Sasson et al., 2009) and to a lesser extent in DS (Whitney et al., 2018). A markedly prevalent aspect in ASD, unlike the population with Down syndrome in separation anxiety, which differs in comparison to typically developing populations. It is clear that for ASD, family figures are more important to them than their peers or other environments (Klein et al., 2018; Stern et al., 2014). In the case of Down syndrome, there is greater difficulty in attributing and recognizing emotions of fear (Cebula,
Wishart, Willis, \& Pitcairn, 2017), which may be related to sleeping alone, or that something bad happens to the parents or to him/herself, for example (items on the $\mathrm{SA}$ ). The items on the SO/PA scale show a difficulty or weakness that people with Down syndrome have in performing introspection on their emotions or what they feel and perceive (Cebula et al., 2017; Flórez et al., 2015).

The internal consistency of the scale's items was high, and the Cronbach's alpha data are similar to those reported in previous studies involving typically developing 
Table 3

\begin{tabular}{lcccccccccccc}
\multicolumn{1}{l}{ Goodness-of-fit indices for the $S C A R E D-D S\left(D S_{A S}=63\right)$} \\
\hline SCARED-DS & $\chi^{2}$ & $\mathrm{df}$ & $\chi^{2} / \mathrm{df}$ & $p$ & $\begin{array}{c}\text { RMSEA } \\
{[95 \% \mathrm{CI}]}\end{array}$ & SRMR & CFI & TLI & GFI & AGFI & AIC \\
\hline Model 1 & 139.12 & 68 & 2.05 & .32 & $\begin{array}{c}.61[.58- \\
.69]\end{array}$ & .83 & .81 & .86 & .61 & .78 & 6645.76 \\
Model 2 & 109.18 & 65 & 1.68 & .02 & $\begin{array}{c}.02[.01- \\
.04]\end{array}$ & .03 & .99 & .98 & .92 & .95 & 3832.89 \\
\hline
\end{tabular}

Note. $\chi^{2}=$ chi squared; $\mathrm{df}=$ degree of freedom, $\chi^{2} / \mathrm{df}=$ chi-squared goodness-of-fit index; $p=$ significance level; RMSEA = root mean square error of approximation; SRMR = standardized root mean square residual; CFI = Comparative Fit Index; TLI = Tucker-Lewis Index; GFI = gamma index; AGFI = adjusted goodness-of-fit index; $\mathrm{AIC}=$ Akaike Information Criteria

\section{Table 4}

Correlations between the $S C A R E D-D S\left(D S_{A S}=63\right)$ and the $S C A S$

\begin{tabular}{lcccccc}
\hline & \multicolumn{2}{c}{ SO/PA SP } & GA & SA & $\begin{array}{c}\text { S- } \\
\text { DS }\end{array}$ & SCAS \\
\hline SO/PA & 1 & $.93^{* *}$ & $.89^{* *}$ & $.70^{* *}$ & $.91^{* *}$ & $.71^{* *}$ \\
SP & $.80^{* *}$ & 1 & $.71^{* *}$ & $.81^{* *}$ & $.94^{* *}$ & $.83^{* *}$ \\
GA & $.80^{* *}$ & $.82^{* *}$ & 1 & $.90^{* *}$ & $.82^{* *}$ & $.88^{* *}$ \\
SA & $.74^{* *}$ & $.89^{* *}$ & $.77^{* *}$ & 1 & $.72^{* *}$ & $.86^{* *}$ \\
S-DS & $.95^{* *}$ & $.96^{* *}$ & $.92^{* *}$ & $.91^{* *}$ & 1 & $.89^{* *}$ \\
SCAS & $.71^{* *}$ & $.83^{* *}$ & $.88^{* *}$ & $.86^{* *}$ & $.89^{* *}$ & 1 \\
\hline
\end{tabular}

Note. $\mathrm{SO} / \mathrm{PA}=$ somatic/panic; $\mathrm{SP}=$ social phobia; $\mathrm{GA}=$ generalized anxiety; $\mathrm{SA}=$ separation anxiety; $\mathrm{S}-\mathrm{DS}=$ SCARED-DS; ${ }^{*}$ correlation significant at 0.05 level; ${ }^{* *}$ correlation significant at 0.01 level; ns $=$ not significant

youth and children with ASD. In general terms, internal consistency and factor structure were consistently robust and support the administration of the SCARED-DS for clinical and research use in children and youth with DS.

\subsection{Limitations}

This study does present some limitations. The size and composition of the sample may limit the generalization of the results, especially with regard to the resulting model as most suitable for confirmatory factorial analysis. The realization of structural equations in small clinical samples can be solved using extraction methods appropriate to the size and not normality of the sample (Hu \& Bentler, 1998; Muthén, 2016). Also, recent studies have suggested that the number of cases per variable in factor analyses should be modified in the adaptation of evaluation instruments in clinical samples (Shi, Lee, \& Maydeu-Olivares, 2019). Furthermore, the cross-sectional design prevents us from making more precise predictions, meaning that a longitudinal approach would need to be adopted in future research to improve the reliability and validity of the SCARED-DS. In addition, the results of this study are only generalizable to a similar population with anxiety.
Future efforts should also focus on determining whether sex and age-related differences exist. Moreover, there is a call for pre-post treatment studies on anxiety in children and youth with DS that use the SCARED-DS as an outcome measure. One final limitation resides in the fact that there are currently no scales that screen anxiety in this population in any language. For this reason, we used the SCAS (Godoy et al., 2011) to diagnose anxiety in our study, aware that no adapted version designed for people with intellectual disability in general, or DS in particular, is available. However, the scale has been successfully applied to people with ASD (Reaven, Blakeley-Smith, Leuthe, Moody, \& Hepburn, 2012), and similar scales have been used on people with intellectual disability (Houtkampa, Van der Molen, Leone de Voogd, Saleminkb, \& Klein, 2017; Klein et al., 2018). Yet all of these limitations are an opportunity to expand on a wide-reaching field of research, in which emotional aspects and not just cognitive aspects can be assessed in this type of population.

\section{Conclusions}

Establishing the validity of the SCARED as a diagnostic tool for youth with SD represents an important step toward meeting the mental health needs of this population with intellectual disabilities (Whitney et al., 2018). Anxiety symptoms are particularly common in children with intellectual disabilities, although to a lesser extent among those with Down syndrome, and contribute to significant morbidity through childhood, adolescence, and adulthood if unrecognized and untreated (Flórez et al., 2015). Accurate and timely assessment of anxiety symptoms is essential in receiving appropriate treatment and, ultimately, in mitigating the negative impact of comorbidity on children's functioning and development.

In short, using a tool such as this test would be useful to evaluate a similar population of young people with Down syndrome in order to send them for treatment. Our study demonstrates the efficacy of SCARED in detecting anxiety symptoms in young people with DS. The SCARED total score can provide a useful method of 
Table 5

Correlations between the $S C A R E D-D S\left(D S_{A S}=63\right)$ and the $S C A S$

\begin{tabular}{|c|c|c|c|c|c|c|c|}
\hline SCARED-DS & M & $\mathrm{SD}$ & $\begin{array}{c}\mathrm{S} \\
\mathrm{SE}(.13)\end{array}$ & $\frac{\mathrm{K}}{\mathrm{SE}(.22)}$ & $\mathrm{K}-\mathrm{S}$ & $r_{x x}$ & $\alpha$ \\
\hline $\mathrm{SO} / \mathrm{PA}$ & 7.29 & 4.41 & -.20 & -1.14 & $.71^{*}$ & .73 & .81 \\
\hline $\mathrm{SP}$ & 7.61 & 2.52 & -.13 & -1.06 & $.89^{* *}$ & .59 & .89 \\
\hline GA & 8.21 & 5.57 & -.16 & -1.09 & $.23^{*}$ & .69 & .72 \\
\hline $\mathrm{SA}$ & 11.21 & 5.34 & -.12 & .1 .11 & $.45^{*}$ & .56 & .86 \\
\hline TOTAL & 20.02 & 11.98 & .92 & -1.22 & $.88^{* *}$ & .76 & .91 \\
\hline
\end{tabular}

Note. $\mathrm{SO} / \mathrm{PA}=$ somatic/panic; $\mathrm{SP}=$ social phobia; $\mathrm{GA}=$ generalized anxiety; $\mathrm{SA}=$ separation anxiety; $\mathrm{M}=$ mean; $\mathrm{SD}=$ standard deviation; $\mathrm{S}=$ skewness; $\mathrm{K}=$ kurtosis; $\mathrm{SE}=$ standard error of skewness and kurtosis; K-S = Kolmogorov-Smirnov test; ${ }^{*}$ Significant $<0,05 ; * *$ Significant $<0,01 ;$ ns $=$ not significant; $r_{x x}=$ Split-half reliability; $\alpha=$ alpha.

detecting clinical anxiety. The ease of use of SCARED supports its use in young people with DS in both clinical and research settings.

\section{Acknowledgements}

The authors gratefully acknowledge the parents and children who participated in our studies.

\section{References}

Achenbach, C., \& Edelbrock, T. M. (1980). A typology of child behavior profile patterns: distribution and correlates for disturbed children aged 6-16. Journal of Abnormal Child Psychology December, 8(4), 441470. doi:10.1007/bf00916500.

American Psychiatric Association. (2006). Amos 7.0 user's guide. Springhouse, PA: Amos Development Corporation.

American Psychiatric Association. (2014). Diagnostic and Statistical Manual of Mental Disorders, Fourth edition, Text revision (DSM-IV-TR). Washington, DC: American Psychiatric Association.

Ben-Sasson, A., Hen, L., Fluss, R., Cermak, S. A., Engel-Yeger, B., \& Gal, E. (2009). A metaanalysis of sensory modulation symptoms in individuals with autism spectrum disorders. Journal of Autism and Developmental Disorders, 39(1), 1-11. doi:10.1007/s10803-008-0593-3.

Birmaher, B., Brent, D. A., Chiappetta, L., Bridge, J., Monga, S., \& Baugher, M. (1999). Psychometric properties of the screen for Child Anxiety Related Emotional Disorders (SCARED): A replication study. Journal of the American Academy of Child and Adolescent Psychiatry, 38, 1230-1236. doi:10.1097/00004583-199910000-00011.

Birmaher, B., Khetarpal, S., Brent, D., Cully, M., Balach, L., Kaufman, J., \& McKenzie-Neer, S. (1997). The Screen for Child Anxiety Related Emotional Disorders (SCARED): Scale construction and psychometric characteristics. Journal of the American
Academy of Child and Adolescent Psychiatry, 36, 545-553. doi:10.1097/00004583-199704000-00018.

Borrel, J. M. (2012). Cuidados de salud en el adulto con síndrome de Down. Revista Española de Pediatría, $68,448-453$.

Cebula, K. R., Wishart, J. G., Willis, D. S., \& Pitcairn, T. K. (2017). Emotion recognition in children with down syndrome: Influence of emotion label and expression intensity. American Journal on Intellectual and Developmental Disabilities, 2, 138155. doi:10.1352/1944-7558-122.2.138.

Chorpita, B. F., Yim, L., Moffitt, C. E., Unemoto, L. A., \& Francis, S. E. (2000). Assessment of symptoms of DSM-IV anxiety and depression in children: A Revised Child Anxiety and Depression Scale. Behavior Change, 19, 90-101.

Cleland, J., Wood, S., Hardcastle, W., Wishart, J., \& Timmins, C. (2010). 'relationship between speech, oromotor, language and cognitive abilities in children with down's syndrome'. International journal of language $\&$ communication disorders / Royal College of Speech 83 Language Therapists, 45(1), 83-95. doi:10.3109/13682820902745453.

Cordero, A., \& Calonge, I. (1997). K-BIT manual: test breve de inteligencia de Kaufman. Madrid: Tea Ediciones.

Couzens, D., Cuskelly, M., \& Haynes, M. (2011). Cognitive Development and Down Syndrome: Age-Related Change on the Stanford-Binet Test (Fourth Edition). American Journal on Intellectual and Developmental Disabilities, 116(3), 181-204. doi:10.1352/1944-7558-116.3.181.

Couzens, D., Haynes, M., \& Cuskelly, M. (2012). Individual and environmental characteristics associated with cognitive development in Down syndrome: a longitudinal study. Journal of Applied Research in Intellectual Disabilities, 25(5), 396413. doi:10.1111/j.1468-3148.2011.00673.x.

Esbensen, A. J., Rojahn, J., Aman, M. G., \& Ruedrich, S. (2003). Reliability and validity of an assessment instrument for anxiety, depression, and mood among 
individuals with mental retardation. Journal of Autism and Developmental Disorders, 36(6), 617629. doi:10.1023/B:JADD.0000005999.27178.55.

Fink, E., Deighton, J., Humphrey, N., \& Wolpert, M. (2015). Assessing the bullying and victimisation experiences of children with special educational needs in mainstream schools: Development and validation of the Bullying Behaviour and Experience Scale. Research in Developmental Disabilities, 36, 611-619. doi:10.1016/j.ridd.2014.10.048.

Flórez, J., Garvía, B., \& Fernández-Olari, R. (2015). Sindrome de Down: Neurobilogía, neuropsicología, salud mental. Madrid: Editorial CEPE.

Foley, K. R., Taffe, J., Bourke, J., Einfeld, S. L., Tonge, B. J., Trollor, J., \& Leonard, H. (2016). Young People with Intellectual Disability Transitioning to Adulthood: Do Behaviour Trajectories Differ in Those with and without Down Syndrome? Plos ONE, 11(7), e0157667. doi:10.1371/journal.pone.0157667.

Garcia-Lopez, L. J., Saez-Castillo, A. J., \& FuentesRodriguez, G. (2016). Psychometric properties of the Youth Anxiety Measure for DSM5, Part I (YAM-5-I) in a community sample of spanish-speaking adolescents. Journal of Affective Disorders, 15(288), 455-459. doi:10.1016/j.jad.2016.10.045.

Garvía, A., Benejam, B., \& Borrel, C. (2010). Guía de Salud Mental en el síndrome de Down. Madrid: Down España.

Godoy, A., Gavino, A., Carrillo, F., Cobos, M. P., \& Quintero, C. (2011). Composición factorial de la versión española de la Spence Children Anxiety Scale (SCAS). Psicothema, 23, 289-294.

Hale, W. W., Crocetti, E., Raaijmakers, Q. A., \& Meeus, W. H. (2011). A meta-analysis of the cross-cultural psychometric properties of the screen for Child Anxiety Related Emotional Disorders (SCARED). Journal of Child Psychology and Psychiatry, 52(1), 80-90. doi:10.1111/j.1469-7610.2010.02285.x.

Hale, W. W., Raaijmakers, Q. A. W., García-López, L. J., Espinosa, L., Muela, J. A., \& Díaz, M. M. (2013). Psychometric properties of the screen for child anxiety related emotional disorders for socially anxious and healthy spanish adolescents. Spanish Journal of Psychology, 16, 1-7.

Houtkampa, E. O., Van der Molen, M. J., Leone de Voogd, E., Saleminkb, E., \& Klein, A. M. (2017). The relation between social anxiety and biased interpretations in adolescents with mild intellectual disabilities. Research in Developmental Disabilities, 67, 94-98. doi:10.1016/j.ridd.2017.06.003.

Hu, L. T., \& Bentler, P. M. (1998). Fit indices in covariance structural modeling: Sensitivity to underparameterized model misspecification. Psychological Methods, 3(4), 424-453.
Hu, L. T., \& Bentler, P. M. (1999). Cutoff Criteria for Fit Indexes in Covariance Structure Analysis: Conventional Criteria Versus New Alternatives. Structural Equation Modeling, 6(1), 1-55.

Isolan, L., Salum, G. A., Osowski, A. T., Amaro, E., \& Manfro, G. G. (2011). Psychometric properties of the screen for Child Anxiety Related Emotional Disorders (SCARED) in Brazilian children and adolescents. Journal of Anxiety Disorders, 25(5), 741-748. doi:10.1016/j.janxdis.2011.03.015.

Klein, A. M., Houtkamp, E. O., Salemink, E., Baartmans, J. M. D., Rinck, M., \& Van der Molen, M. J. (2018). Differences between self- and peer-rated likability in relation to social anxiety and depression in adolescents with mild intellectual disabilities. Research in Developmental Disabilities, 80, 44-51. doi:10.1016/j.ridd.2018.05.016.

Kline, R. B. (2016). Principles and practice of structural equation modeling (4rd ed.). New York: The Guilford Press.

Lanfranchi, S., A., B., S., G., \& R., V. (2012). Working memory in Down syndrome: is there a dual task deficit? Journal of Intellectual Disability Research, 56(2), 157-166. doi:10.1111/j.13652788.2011.01444.x.

Mazzone, L., Ruta, L., \& Reale, L. (2012). Psychiatric comorbidities in Asperger syndrome and high functioning autism: Diagnostic challenges. Annals of General Psychiatry, 11(1), 16. doi:10.1186/1744859X-11-16.

Muris, P., Simon, E., Lijphart, H., Bos, A., Hale, W., Schmeitz, K., \& and Adolescent Anxiety Assessment Expert Group, I. C. (2017). The Youth Anxiety Measure for DSM-5 (YAM-5): development and first psychometric evidence of a new scale for assessing anxiety disorders symptoms of children and adolescents. Child Psychiatry 83 Human Development, 48(1), 1-17. doi:10.1007/s10578-0160648-1.

Muthén, B. (2016). Goodness of fit with categorical and other nonormal variables. In Bollen, K.A. 83 Long, J.S.. Testing Structural Equation Models (pp. 205-234). Edited Newbury Park, CA: Sage.

Naess, K. A., Melby-Lervåg, M., Hulme, C., \& Lyster, S. A. (2012). Reading skills in children with down syndrome: a meta-analytic review. Research in Developmental Disabilities, 33(2), 737747. doi:10.1016/j.ridd.2011.09.019.

Olofsdotter, S., Sonnby, K., Vadlin, S., Furmark, T., \& Nilsson, K. W. (2016). Assessing Adolescent Anxiety in General Psychiatric Care: Diagnostic Accuracy of the Swedish Self-Report and Parent Versions of the Spence Children's Anxiety Scale. Assessment, 23(6), 744-757. doi:10.1177/1073191115583858.

Orgilés, M., Fernández-Martínez, I., Guillén-Riquelme, 
A., Espada, J. P., \& Essau, C. A. (2016). A systematic review of the factor structure and reliability of the spence Children's Anxiety Scale. Journal of Affective Disorders, 190, 333-340.

Orgilés, M., Méndez, X., Spence, S., Huedo-Medina, T. B., \& Espada, J. P. (2011). Spanish Validation of the Spence Children's Anxiety Scale. Child Psychiatry \& Human Development, 43, 271-281. doi:10.1007/s10578-011-0265-y.

Piqueras, J., Martín-Vivar, M., Sandin, B., San Luis, C., \& Pineda, D. (2017). The Revised Child Anxiety and Depression Scale: A systematic review and reliability generalization meta-analysis. The Journal Affective Disorders, 218, 153-169. doi:10.1016/j.jad.2017.04.022.

Reaven, J., Blakeley-Smith, A., Leuthe, E., Moody, E., \& Hepburn, S. (2012). Facing your fears in adolescence: Cognitive-behavioral therapy for highfunctioning autism spectrum disorders and anxiety. Autism Research and Treatment, 423905, 1-13. doi:10.1155/2012/423905.

Robles-Bello, M. A., Valencia, N., \& Sánchez-Teruel. (2018). Learning potential is useful in pre-schoolers with fragile $\mathrm{x}$ and down syndrome. Psicolgía Educativa/Educational Psychology, 24(2), 51-57. doi:10.5093/psed2018a8.

Rodríguez-Ayán, M. A., \& Ruiz-Díaz, M. A. (2008). Atenuación de la asimetría y de la curtosis de las puntuaciones observadas mediante transformaciones de variables: Incidencia sobre la estructura factorial [Attenuation of the asymmetry and kurtosis of the scores observed by means of variable transformations: Incidence on the factorial structure]. Psicológica, 29(2), 205-227.

Sandín, B., Valiente, R. M., \& Chorot, P. (2009). RCADS: Evaluación de los síntomas de ansiedad y depresión en niños y adolescentes [RCADS: Assessment of Anxiety and Depression Symptoms in Children and Adolescents]. Revista de Psicopatología y Psicología Clínica, 14(3), 193-206.

Sentenac, M., Gavin, A., Arnaud, C., Molcho, M., Godeau, E., \& Gabhainn, S. N. (2011). Victims of bullying among students with a disability or chronic illness and their peers: A cross-national study between ireland and france. Journal of Adolescent Health, 48, 461-466. doi:10.1016/j.jadohealth.2010.07.031.

Shi, D., Lee, T., \& Maydeu-Olivares, A. (2019). Understanding the model size effect on sem fit indices. Educational and psychological measurement, 79(2), 310-334.

Simonoff, E., Pickles, A., Charman, T., Chandler, S., Loucas, T., \& Baird, G. (2008). Psychiatric disorders in children with autism spectrum disorders: Prevalence, comorbidity, and associated factors in a population-derived sam- ple. Journal of the American Academy of Child \& Adolescent Psychiatry, 47(8), 921-929. doi:10.1097/CHI.0b013e318179964f.

Spence, S. H. (1997). Structure of anxiety symptoms among children: A confirmatory factor-analytic study. Journal of Abnormal Psychology, 106, 280297.

Stern, J. A., Gadgil, M. S., Blakeley-Smith, A., Reaven, J. A., \& Hepburn, S. L. (2014). Psychometric properties of the SCARED in youth with autism spectrum disorder. Research in Autism Spectrum Disorders, 8, 1225-1234. doi:10.1016/j.rasd.2014.06.008.

Su, L., Wang, K., Fan, F., Su, Y., \& Gao, X. (2008). Reliability and validity of the screen for child anxiety related emotional disorders (SCARED) in Chinese children. Journal of Anxiety Disorders, 22(4), 612621. doi:10.1016/j.janxdis.2007.05.011.

Van-Steensel, F. J., Deutschman, A. A., \& Bögels, S. M. (2013). Examining the Screen for Child AnxietyRelated Emotional Disorder-71 as an assessment tool for anxiety in children with high-functioning autism spectrum disorders. Autism, 17, 681-692. doi:10.1177/1362361312455875.

Vigil-Colet, A., Canals Sans, J., Cosí, S., Lorenzo-Seva, U., Piera, F., Joan, P., \& Domènech, E. E. (2009). The factorial structure of the 41-item version of the Screen for Child Anxiety Related Emotional Disorders (SCARED) in a Spanish population of 8 to 12 years-old. International Journal of Clinical and Health Psychology, 9(2), 313-327.

White, S. W., Oswald, D., Ollendick, T., \& Scahill, L. (2009). Anxiety in children and adolescents with autism spectrum disorders. Clinical Psychology Review, 29(3), 216-229. doi:10.1016/j.cpr.2009.01.003.

Whiteside, S. P., \& Brown, A. M. (2008). Exploring the utility of the Spence Children's Anxiety Scales parent-and child-report forms in a North American sample. Journal of Anxiety Disorders, 22(8), 14401446. doi:10.1016/j.janxdis.2008.02.006.

Whitney, D. G., Shapiro, D. N., Warschausky, S. A., Hurvitz, E. A., \& D., P. M. (2018). The contribution of neurological disorders to the national prevalence of depression and anxiety problems among children and adolescents. Annals of Epidemiology, 29(8), 81-84. doi:10.1016/j.annepidem.2018.11.003. 


\section{Appendix}

SCARED-DS

\begin{tabular}{ccc}
\hline CASI & A VECES & $\begin{array}{c}\text { MUY A } \\
\text { MENUDO }\end{array}$ \\
\hline
\end{tabular}

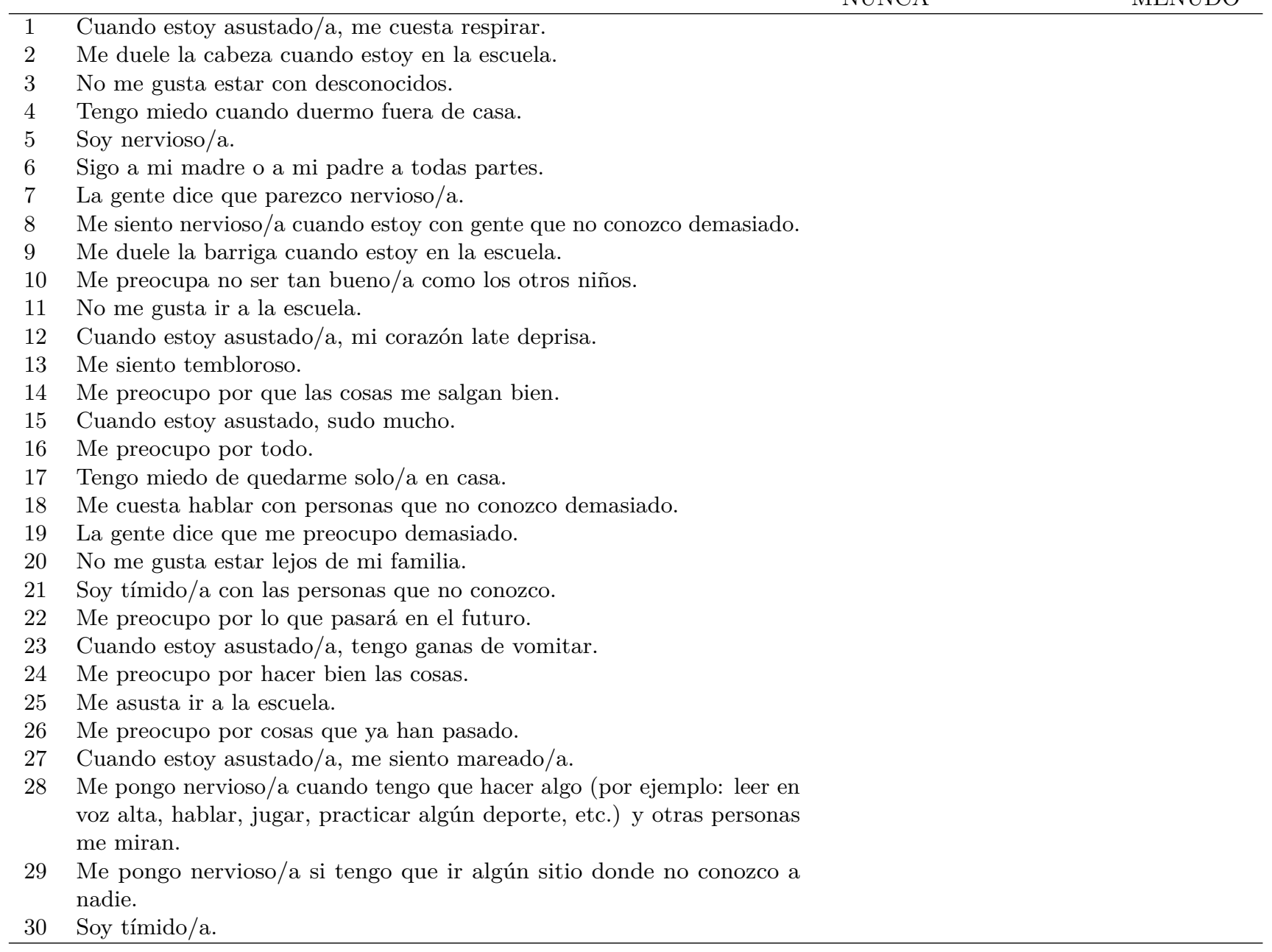

